\title{
HBX-Mediated Migration of HBV-Replicating HepG2 Cells: Insights on Development of Hepatocellular Carcinoma
}

\author{
Huixing Feng, Jianhua Zhang, Xi Li, and Wei Ning Chen \\ School of Chemical and Biomedical Engineering, Nanyang Technological University, Singapore 637459 \\ Correspondence should be addressed to Wei Ning Chen, wnchen@ntu.edu.sg \\ Received 11 February 2009; Revised 5 May 2009; Accepted 6 July 2009 \\ Recommended by Shahid Jameel
}

\begin{abstract}
Hepatitus B virus (HBV) is a major cause of the development of hepatpcellular carcinoma (HCC). One of the significant characteristics of tumor progression is cell migration which is reflective of cytoskeletal dynamics. The Rho GTPases contribute to a multiple cellular processes, including the cellular cytoskeletal reorganization and motility. It has been found that some Rho GTPases have oncogenic activity and can promote cancer cell invasion. Here we discuss one of the Rho GTPases, Racl can be activated by HBV replication and such activation results in the high motility of HBV-replicating cells. The enhanced cell motility can be interestingly alleviated by the mutation at the sites of proline rich domain located in HBX. Our findings may provide new insights on the mechanism of HCC development associated with chronic HBV infection.
\end{abstract}

Copyright (C) 2009 Huixing Feng et al. This is an open access article distributed under the Creative Commons Attribution License, which permits unrestricted use, distribution, and reproduction in any medium, provided the original work is properly cited.

\section{Introduction}

Hepatitis B virus (HBV) can cause chronic and acute infection and remains a global health problem with a considerable morbidity and mortality. It was estimated that there are currently more than 350 million carriers all over the world [1]. Chronic hepatitis B virus (HBV) infection is a major cause of hepatocellular carcinoma (HCC) [2]. HBV chronic carriers, including those carrying vaccine-escape mutants [3], have a greater than 100-fold increased relative risk of developing the tumor [4]. Despite characterization of integrated HBV genome in chromosomes of HCC [5], a comprehensive understanding of the underlying mechanism needs further elucidation.

Tumor progression is a complex multistage process, making the cells from normal to malignant by a series of alterations including cell adhesion and movements. One of the important characteristics of the tumor cells is that they have the ability to escape from the normal controls during proliferation, differentiation, apoptosis, and migration [6]. In metastasis, tumor cells detached from their place of formation, move, and form new tumors in distant healthy tissues.

Cell migration is a key activity of many important normal and abnormal biological processes, including tumor cell metastasis [7]. Invasion and metastasis are essential hallmarks of malignant cancer cells. Adhesion of tumor cells to host cell layers and subsequent transcellular migration are important processes in cancer invasion and metastasis, which involves the extracellular matrix (ECM) degradation [8-10]. High motility and cell migration might be the premonition of malignancy of chronic viral infection.

The Rho small GTPases, which contains the Rho, Rac, Cdc42 subfamilies, regulate cell migration through the reorganization of actin cytoskeleton, which is considered as a driving force of cell motility $[11,12]$. The Rho GTPases act as molecular switches cycling between active GTP-bound forms and inactive GDP-bound forms [13]. Such cycling is regulated by guanosines nucleotide exchange factors (GEFs) and GTPase-activating proteins (GAPs) [14]. The Rho family has been implicated in many steps during the cellular transformation. In addition, Rho GTPases activation has been linked to virus replication such as HIV-1, HSV (Herpes Simplex Virus) and HBV [15-17]. Rho A, Rho C, and Rac1 have been reported significantly elevated in a variety of tumors, especially in the more metastatic forms $[18,19]$.

During the tumor progression, the loss of the cell characteristics results in morphological changes, such as cell-cell adhesion, gene expression, and motility rate. For example, the adhesion velocity has been shown to be affected by HBV replication [20]. Our laboratory has recently reported that 


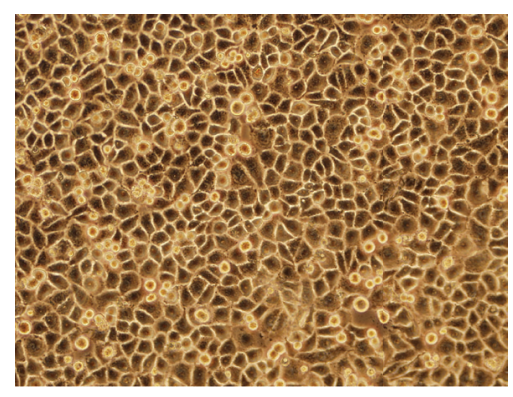

(a)

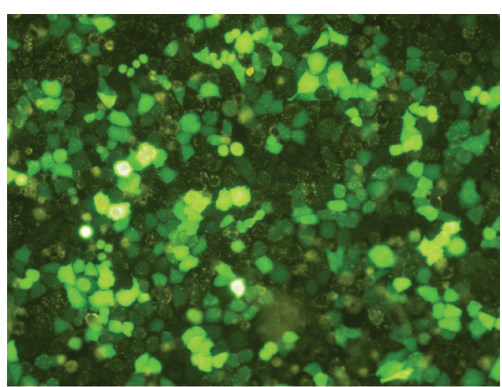

(b)

FIGURE 1: Transfection of HepG2 cells using Amaxa Nucleofector and monitored by transient transfection of pEGFP vector: (a) phase contrast image of cells 48 hours after transfection: (b) the corresponding image of the green fluorescent by pEGFP in the same field (Olympus IX71 fluorescent microcopy).

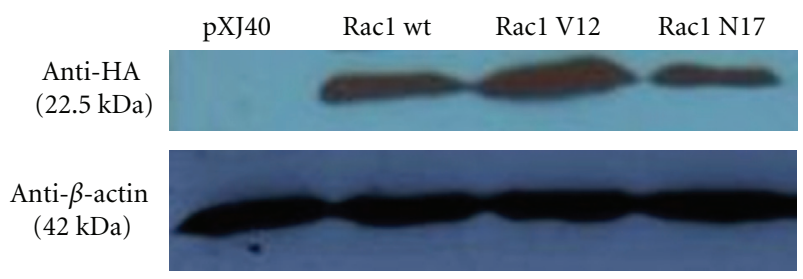

(a)
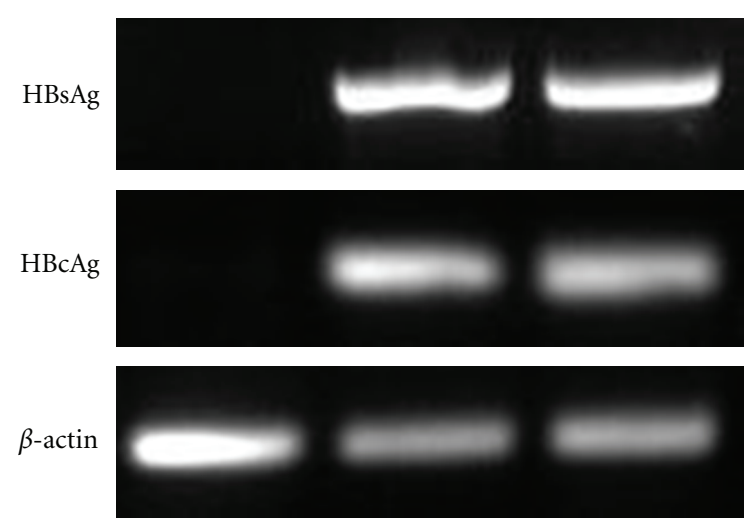

(b)

Figure 2: Western blot analysis, (a) expression of Rac1 wt, Rac1 ${ }^{\text {G12V }}$, and $\operatorname{Racl}^{\mathrm{T} 17 \mathrm{~N}}$ by western blotting. The internal control was $\beta$-actin, (b) RT-PCR on the expression of HBsAg and HBcAg of Wildtype HBV replicative genome and $\mathrm{P}-\mathrm{A}$ mutant $\mathrm{HBV}$ genome. The negative controls was HepG2 cells transfected by empty vector pcDNA3.1. $\beta$-actin was the internal control.

HBV-replicating HepG2 cells display similar morphology with those expressing the constitutively activated Rac1, mediated by $\mathrm{HBx}$ [17]. We have also shown that HBV can activate Racl GTPases and induce membrane ruffling. HBX can directly interact with a Racl nucleotide exchange factor $\beta$ PIX, by an SH3 binding motif and affect the cell morphology [17]. Our data are in line with earlier reports on the potential invasion ability of HBX through indirect activation of matrix metalloproteinase (MMPs) [21, 22]. We now report that the Rac1 GTPase was involved synergistically with HBX in the migration of HBV-replicating cells. Our findings should provide new insights on the mechanism of development of HCC.

\section{Materials and Methods}

2.1. Plasmids Construction and DNA Manipulation. The replicative $\mathrm{HBV}$ genome comprising a $3.5 \mathrm{~kb}$ linear fragment was constructed as described [23] in mammalian expression vector pcDNA3.1 (Invitrogen, USA), using a two step cloning strategy.

Wild-type replicative HBV genome was used as template to generate proline to alanine mutation by sitedirected mutagenesis as described in [17]. Four prolines in $\mathrm{HBX}$ on the replicative genome were mutated into alanine: $\quad$ ESRGR $^{29} \underline{\text { PLPG }^{33}}$ PLGALPPAS $^{42} \underline{\mathrm{P}}^{43} \underline{\text { PIVPTDH to }}$ ESRGR $^{29}{ }^{\text {ALPG }}{ }^{33} \underline{A}{ }_{\text {LGALPPAS }}^{42} \underline{A}^{43} \underline{\text { AIVPTDH. }}$. Mutations were confirmed by DNA sequencing.

The plasmids of Rac1 wide type, constitutively activated $\mathrm{Racl}^{\mathrm{G} 12 \mathrm{~V}}$, and dominant negative Racl ${ }^{\mathrm{T} 17 \mathrm{~N}}$ were constructed into a mammalian vector pXJ40 with a HA tag at $N$-terminal as described in $[24,25]$.

2.2. Cell Culture and Transfection. HepG2 cells were maintained and passaged in Gibco Dulbecco's Minimal Essential Medium, supplemented with 10\% fetal bovine serum, 1\% antimycotic, and controlled 5\% $\mathrm{CO}_{2}$. Transfections were performed using Nucleofection solution V (Amaxa GmBH) as described in [17].

2.3. RNA Extraction and RT-PCR. RNA of the HepG2 cells transfected with various plasmids was extracted using RNeasy Mini kit (QIAGEN, USA) as described in [17]. DNase I digestion were applied to the extracted RNA to remove genome DNA contamination. The concentration and quality of RNA were obtained by the absorbance at $\mathrm{OD}_{260}$ and the absorbance ratio of $\mathrm{OD}_{260}$ and $\mathrm{OD}_{280}$.

RT-PCR was performed to confirm gene expression from the replicative $\mathrm{HBV}$ genome as described in [17]. 


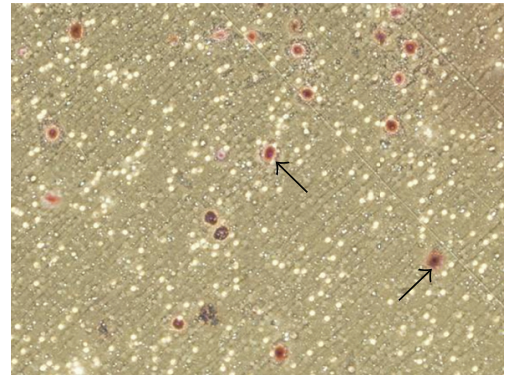

(a)

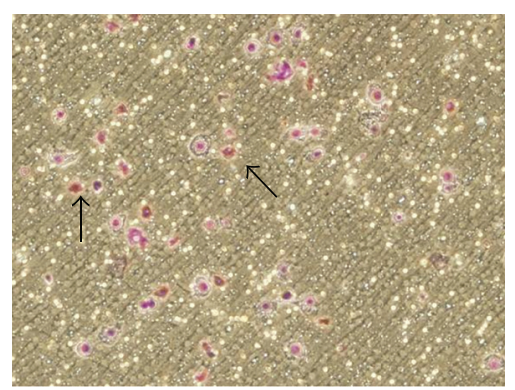

(d)

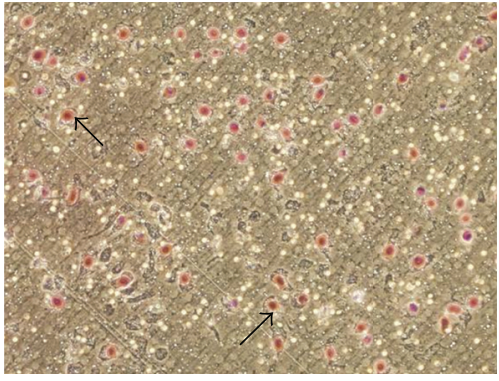

(b)

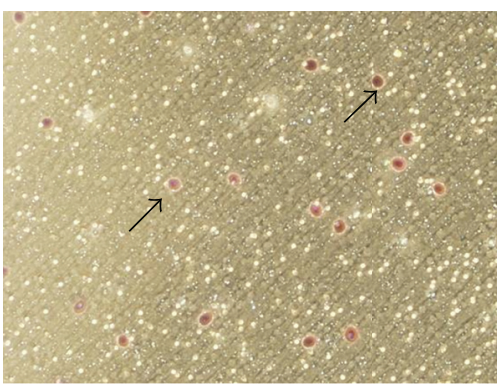

(e)

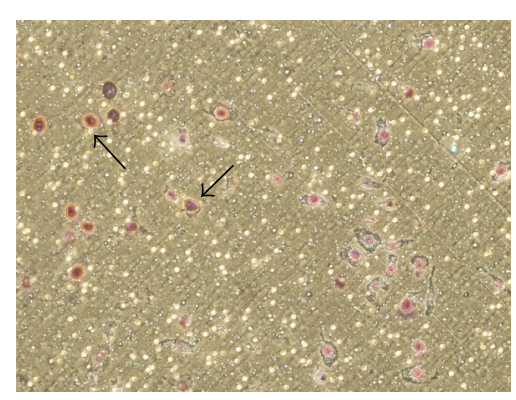

(g)

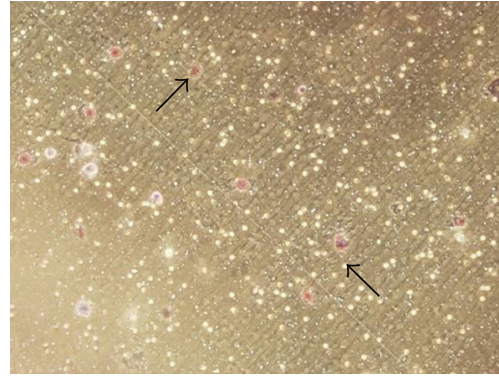

(c)

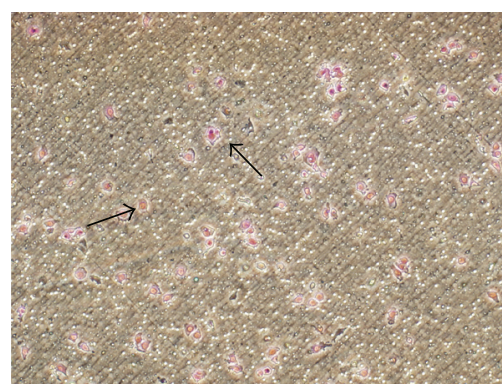

(f)

Figure 3: Cell motility assay: microscopic examination of cells (red dots by staining) migrated from the upper side to the lower side of the collagen-coated membrane (Olympus IX 71 microscope). Representative cells were indicated by arrow heads. (a) HepG2 cells transfected by Wild-type Rac1; (b) HepG2 cells transfected with Rac1 ${ }^{\text {G12V }}$; (c) HepG2 cells transfected by Rac1 ${ }^{\text {T17N }}$; (d) HepG2 cells transfected with Wild-type Rac1 and Wild-type HBV genome; (e) HepG2 cells transfected with Rac1 wt and P-A mutant HBV genome; (f) HepG2 cells transfected with Wild-type HBV genome; (g) HepG2 cells transfected with P-A mutant HBV genome.

The primers used for RT-PCR were as follows:

$\beta$-actin forward: $5^{\prime}$-CTTAGTTGCGTTACACCCTTTC-3',

$\beta$-actin reverse: $5^{\prime}$-ACCTTCACCGTTCCAGTTTT$3^{\prime}$,

HBsAg forward: 5'-TCACCATATTCTTGGGAACAA-3',

HBsAg reverse: $5^{\prime}$-GTTTTGTTAGGGTTTAAATG$3^{\prime}$,

HBcAg forward: $5^{\prime}$-ATCTCCTAGACACCGCCTCA-3',

HBcAg reverse: $5^{\prime}$-TTCCAAATTATTACCCACCC$3^{\prime}$.

2.4. Western Blot Analysis. HepG2 cells transfected with individual constructs were collected 48 hours after transfection.
Total protein was extracted by cell lysis buffer. Western blot analysis was carried out using specific anti-HA or anti-actin antibodies as described [17].

2.5. Cell Motility by Transwell Assay. Cell motility was assessed by Transwell Migration Assay kit (BD Falcon, USA). The inserts were put into the 24-well plate and both sides of the membrane of the inserts were coated with collagen (Bioscience, USA) for more than 2 hours. 36 to 48 hours after transfection, the HepG2 cells were trypsinized and cell number was adjusted to $20,000-30,000$ cells per $200 \mu \mathrm{l}$ volume by cell numbering. The cell suspension was deposited onto the collagen-coated membrane in each insert in the 24well plate. The plate was put into $37^{\circ} \mathrm{C}, 5 \% \mathrm{CO}_{2}$ incubator and cultured for 8 hours to overnight. This was needed to allow cell migration to take place, from the upper side to the lower side of the collagen-coated membrane. The 


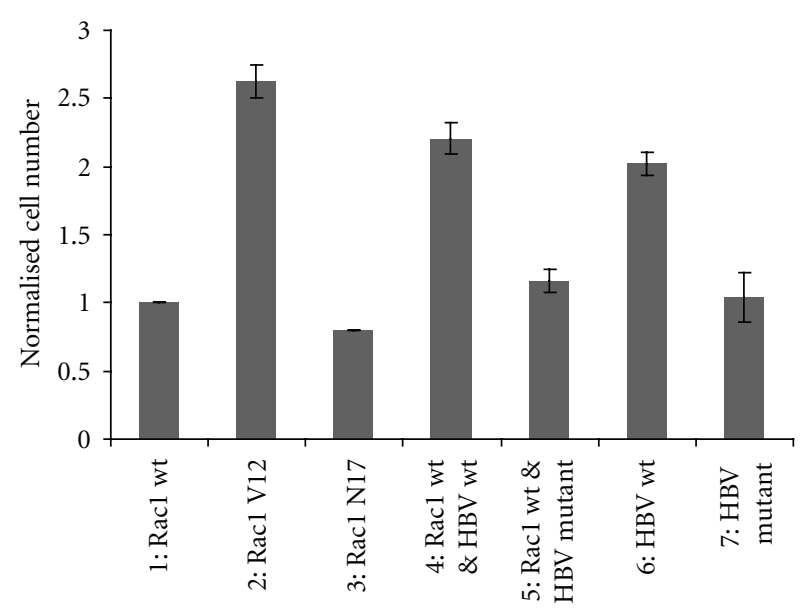

FIGURE 4: Graphical representation of cell motility: lane 1, motility of cells expressing wild-type Racl alone (indicated as Racl wt); lane 2, cells expressing constitutively activated Racl ${ }^{\mathrm{G} 12 \mathrm{~V}}$ (indicated as Rac1 V12); lane 3, cells expressing dominant negative Rac1 ${ }^{\mathrm{T} 17 \mathrm{~N}}$ (indicated as Rac1 N17); lane 4, cells coexpressing Wild-type Rac1 and Wild-type replicative HBV genome (indicated as Rac1 wt \& HBV wt); lane 5, cells expressing Wild-type Racl and P-A mutant replicative HBV genome (indicated as Racl wt \& HBV mutant); lane 6, cells expressing wile type replicative HBV genome (indicated as $\mathrm{HBV} \mathrm{wt}$ ); lane 7 , cells expressing $\mathrm{P}-\mathrm{A}$ mutant replicative $\mathrm{HBV}$ genome (indicated as HBV mutant).

Table 1: Normalized densities of the bands in Figure 2(a). The densities of Rac1 wt were taken as 1 fold.

\begin{tabular}{lcccc}
\hline Antibody & pXJ40 & Rac1 wt & Rac1 V12 & Rac1 N17 \\
\hline Anti-HA & 0 & 1 & 1.148 & 0.818 \\
Anti- $\beta$-actin & 1.076 & 1 & 1.034 & 1.028 \\
\hline
\end{tabular}

medium was then removed and the upside cells of the inserts were gently mopped with cotton bars. The cells at the lower side of the membrane were fixed with $100 \%$ methanol for 15 minutes. The cells were stained with 0.04\% Giemsa solution (Sigma Aldrich, USA) for 10-15 minutes. The membrane was washed with saline solution and dried up. Four fields were randomly selected in each insert for counting and microscopic images were taken. Three independent experiments were carried out for cells transfected with each type of construct.

\section{Results}

HepG2 cells were transfected using Nucleofector to achieve high efficiency of transfection, as indicated by the high percentage of cells expressing EGFP (Figure 1).

The expression of HBsAg from the replicative genome in transfected HepG2 cells was assessed by RT-PCR, whereas the expression of Wild-type Rac1, Rac1 ${ }^{\mathrm{G} 12 \mathrm{~V}}$, Rac1 ${ }^{\mathrm{T} 17 \mathrm{~N}}$ was determined by Western blot analysis using anti-HA antibody.How ever $\beta$-actin was used as an internal control. Results were shown in Figure 2 and Table 1 showed the normalized densities of the bands shown in Figure 2(a). The density levels of Rac1 wt were used as standards, other bands were normalized based on it. It indicated that all three constructs of Rac1 GTPase were successfully expressed in HepG2 cells at comparable level. In addition, both HBsAg and HBV core antigen ( $\mathrm{HBcAg}$ ) could be detected in HepG2 cells transfected by replicative HBV genome (lane 2, Figure 2(b)) and P-A mutant HBV (lane 3, Figure 2(b)), with the empty vector pcDNA3.1 used as control (lane 1, Figure 2(b)).

The motility of HepG2 cells expressing Rac1 alone, and those expressing both Rac1 and replicative HBV genome was then analysed by transwell assay, as indicated by the number of cells migrated to the lower side of the collagen-coated membrane (see Section 2). Seven sets of constructs were used in this analysis: Wild-type Racl alone; constitutively activated Rac1 ${ }^{\mathrm{G} 12 \mathrm{~V}}$ alone; dominant negative Rac1 ${ }^{\mathrm{T} 17 \mathrm{~N}}$ alone; Wild-type Rac1 and Wild-type HBV genome; Wild-type Rac1 and P-A mutant HBV genome; Wild-type HBV genome alone; and P-A mutant HBV genome alone. Results shown in Figure 3 indicated that HepG2 cells displayed differential motility depending on the transfected constructs, with the highest number of cells (indicated by arrow heads) in cells transfected either with Rac1 ${ }^{\mathrm{G} 12 \mathrm{~V}}$ alone (Figure 3(b)) or with Wild-type Rac1/Wild-type HBV genome (Figure 3(d)). A graphical representation of the motility assay was summarized in Figure 4 after cell counting and analysis. HepG2 cells transfected with the constitutively activated Rac1 ${ }^{\mathrm{G} 12 \mathrm{~V}}$ showed a 2.5 -fold increase in cell motility (lane 2, Figure 4) as compared with those expressing Wild-type Racl alone (lane 1, Figure 4) or those expressing the dominant negative $\mathrm{Rac1}^{\mathrm{T} 17 \mathrm{~N}}$ (lane 3, Figure 4). Interestingly, cells co-transfected with Wild-type Rac1 and replicative HBV genome showed similar motility as those transfected with constitutively activated Rac1 ${ }^{\mathrm{G} 12 \mathrm{~V}}$. This suggested that the cell motility was enhanced by HBV replication, likely via activation of Wildtype Rac1 to its GTP-bound state as recently reported [17]. To validate our findings, the P-A mutant HBV genome (with four proline residues mutated to alanine residues in the proline rich domain) was co-transfected with the Wildtype Rac1. Results shown in Figure 4 (lane 5) indicated that the P-A mutant HBV genome abrogated the cell motility significantly, to a level comparable with expressing cells. Meanwhile, the expression of replicative HBV genome itself enhanced the cell migration also (lane 6), which may imply the endogenous Racl activation by the HBV replication. Not surprisingly, the P-A mutant HBV genome abrogated the cell motility (Lane 7). How ever the cell migration level caused by endogenous Rac1 was less than that caused by the overexpressed Rac1 V12, which suggested that endogenous Wild-type Racl was not sufficient for the activation caused by HBV replication. And such activation was confirmed by the augmentation of cell movements induced by overexpression of Rac1 wt. In other words, the endogenous Rac1 was enough to be activated by HBV replication and passed away cellular signal inducing high cell motility, but the overexpressed Racl can even increase such activation in a certain degree.

Taken together, our results suggested that the cell migration can be caused by HBV replication through the activation of Rac1 GTPase. 


\section{Discussion}

Rho GTPases comprise a family of proteins which are highly conserved from lower eukaryotes to plants and animals [26]. Rho GTPases were implicated in various cellular processes including cytoskeletal reorganization, cell cycle and division, motility, angiogenesis, and phagocytosis [27]. For cytoskeletal reorganization, processes such as cell adhesion, cell migration, cell polarity, spindle formation and locomotion were covered.

It has been reported that the HBX activates ERKs and PI-3k/akt pathways25, and further activates matrix metalloproteinase-919 with a potential function of invasion and metastasis. We have recently demonstrated the same activation of ERK1/2 and AKT by HBX using SH3 binding domain located in HBX. Our recent investigation has also indicated that Racl GTPase can be activated by HBV replication, which in turn sustains HBV replication [17]. Interestingly, the activation of Rac1 and HBV replication has been found to be significantly decreased in cells transfected with P-A mutant HBV genome. Our findings can be further validated by careful design of HBx knockdown in the context of the whole HBV genome, without affecting the proper viral replication. Furthermore, the involvement of Racl can be supported by titration experiments in which the same amount of HBV genome is introduced into the cells with various amount of Racl (activated $\mathrm{V}^{12}$ or inactivated $\mathrm{N}^{17}$ ).

Findings in this report have provided an extension on the consequences of the Racl activation by HBV replication, in terms of cell motility. To our knowledge, this is the first report to show the potential relationship between proline rich domain in HBX (in the context of HBV replication) and cell motility, and should shed new lights on the understanding of the mechanism of HCC development.

\section{Acknowledgments}

This work was supported by Academic Research Fund, Ministry of Education Singapore (RG42/05 to W. N. Chen). $\mathrm{H}$. Feng and X. Li are recipients of graduate scholarship from Nanyang Technology University. J. H. Zhang is the recipient of Singapore Millennium Foundation Graduate Scholarship.

\section{References}

[1] P. Arbuthnot and M. Kew, "Hepatitis B virus and hepatocellular carcinoma," International Journal of Experimental Pathology, vol. 82, no. 2, pp. 77-100, 2001.

[2] D. Ganem and H. E. Varmus, "The molecular biology of the hepatitis B viruses," Annual Review of Biochemistry, vol. 56, pp. 651-693, 1987.

[3] C. J. Oon, W. N. Chen, K. S. Goo, and K. T. Goh, "Intrafamilial evidence of horizontal transmission of hepatitis B virus surface antigen mutant G145R," The Journal of Infection, vol. 41, no. 3, pp. 260-264, 2000.

[4] B. S. Blumberg, B. Larouze, W. T. London, et al., "The relation of infection with the hepatitis B agent to primary hepatic carcinoma," The American Journal of Pathology, vol. 81, no. 3, pp. 669-682, 1975.
[5] W. N. Chen, C. J. Oon, A. L. Leong, S. Koh, and S. W. Teng, "Expression of integrated hepatitis B virus $\mathrm{X}$ variants in human hepatocellular carcinomas and its significance," Biochemical and Biophysical Research Communications, vol. 276, no. 3, pp. 885-892, 2000.

[6] E. Lozano, M. Betson, and V. M. M. Braga, "Tumor progression: small GTpases and loss of cell-cell adhesion," Bioessays, vol. 25, no. 5, pp. 452-463, 2003.

[7] C. D. Nobes and A. Hall, "Rho GTPases control polarity, protrusion, and adhesion during cell movement," The Journal of Cell Biology, vol. 144, no. 6, pp. 1235-1244, 1999.

[8] J. F. Woessner Jr., "Matrix metalloproteinases and their inhibitors in connective tissue remodeling," The FASEB Journal, vol. 5, no. 8, pp. 2145-2154, 1991.

[9] J. A. Varner and D. A. Cheresh, "Integrins and cancer," Current Opinion in Cell Biology, vol. 8, no. 5, pp. 724-730, 1996.

[10] B. M. Gumbiner, "Cell adhesion: the molecular basis of tissue architecture and morphogenesis," Cell, vol. 84, no. 3, pp. 345357, 1996.

[11] D. A. Lauffenburger and A. F. Horwitz, "Cell migration: a physically integrated molecular process," Cell, vol. 84, no. 3, pp. 359-369, 1996.

[12] T. J. Mitchison and L. P. Cramer, "Actin-based cell motility and cell locomotion," Cell, vol. 84, no. 3, pp. 371-379, 1996.

[13] A. B. Jaffe and A. Hall, "Rho GTPases: biochemistry and biology," Annual Review of Cell and Developmental Biology, vol. 21, pp. 247-269, 2005.

[14] J. L. Bos, H. Rehmann, and A. Wittinghofer, "GEFs and GAPs: critical elements in the control of small G proteins," Cell, vol. 129, no. 5, pp. 865-877, 2007.

[15] X. Lu, X. Wu, A. Plemenitas, et al., "CDC42 and Racl are implicated in the activation of the Nef-associated kinase and replication of HIV-1," Current Biology, vol. 6, no. 12, pp. 1677$1684,1996$.

[16] S. Hoppe, M. Schelhaas, V. Jaeger, T. Liebig, P. Petermann, and D. Knebel-Mörsdorf, "Early herpes simplex virus type 1 infection is dependent on regulated Rac1/Cdc42 signalling in epithelial MDCKII cells," Journal of General Virology, vol. 87, no. 12, pp. 3483-3494, 2006.

[17] T. L. Tan, N. Fang, T. L. Neo, et al., "Rac1 GTPase is activated by hepatitis $\mathrm{B}$ virus replication-involvement of HBX," Biochimica et Biophysica Acta, vol. 1783, no. 3, pp. 360374, 2008.

[18] E. A. Clark, T. R. Golub, E. S. Lander, and R. O. Hynes, "Genomic analysis of metastasis reveals an essential role for RhoC," Nature, vol. 406, no. 6795, pp. 532-535, 2000.

[19] N. Hakuma, I. Kinoshita, Y. Shimizu, et al., "E1AF/PEA3 activates the Rho/Rho-associated kinase pathway to increase the malignancy potential of non-small-cell lung cancer cells," Cancer Research, vol. 65, no. 23, pp. 10776-10782, 2005.

[20] T. L. Tan, Z. Feng, Y. W. Lu, V. Chan, and W. N. Chen, "Adhesion contact kinetics of HepG2 cells during hepatitis B virus replication: involvement of SH3-binding motif in HBX," Biochimica et Biophysica Acta, vol. 1762, no. 8, pp. 755-766, 2006.

[21] T.-W. Chung, S.-K. Moon, Y.-C. Lee, J.-G. Kim, J.-H. Ko, and C.-H. Kim, "Enhanced expression of matrix metalloproteinase-9 by hepatitis B virus infection in liver cells," Archives of Biochemistry and Biophysics, vol. 408, no. 2, pp. 147-154, 2002.

[22] E. Lara-Pezzi, P. L. Majano, M. Yáñez-Mó, et al., "Effect of the hepatitis B virus $\mathrm{HBx}$ protein on integrin-mediated adhesion to and migration on extracellular matrix," Journal of Hepatology, vol. 34, no. 3, pp. 409-415, 2001. 
[23] P. Hong, L. F. P. Ng, E. C. Ren, and W. N. Chen, "A cellbased system for hepatitis B virus replication: significance of clinically enhanced viral replication in relation to deletions in viral core promoter," Frontiers in Bioscience, vol. 10, supplement 1, pp. 2001-2004, 2005.

[24] E. Manser, T.-H. Loo, C.-G. Koh, et al., "PAK kinases are directly coupled to the PIX family of nucleotide exchange factors," Molecular Cell, vol. 1, no. 2, pp. 183-192, 1998.

[25] C.-G. Koh, E. Manser, Z.-S. Zhao, C.-P. Ng, and L. Lim, "Beta1PIX, the PAK-interacting exchange factor, requires localization via a coiled-coil region to promote microvilluslike structures and membrane ruffles," Journal of Cell Science, vol. 114, no. 23, pp. 4239-4251, 2001.

[26] A. Boureux, E. Vignal, S. Faure, and P. Fort, "Evolution of the Rho family of ras-like GTPases in eukaryotes," Molecular Biology and Evolution, vol. 24, no. 1, pp. 203-216, 2007.

[27] S. Etienne-Manneville and A. Hall, "Rho GTPases in cell biology," Nature, vol. 420, no. 6916, pp. 629-635, 2002. 

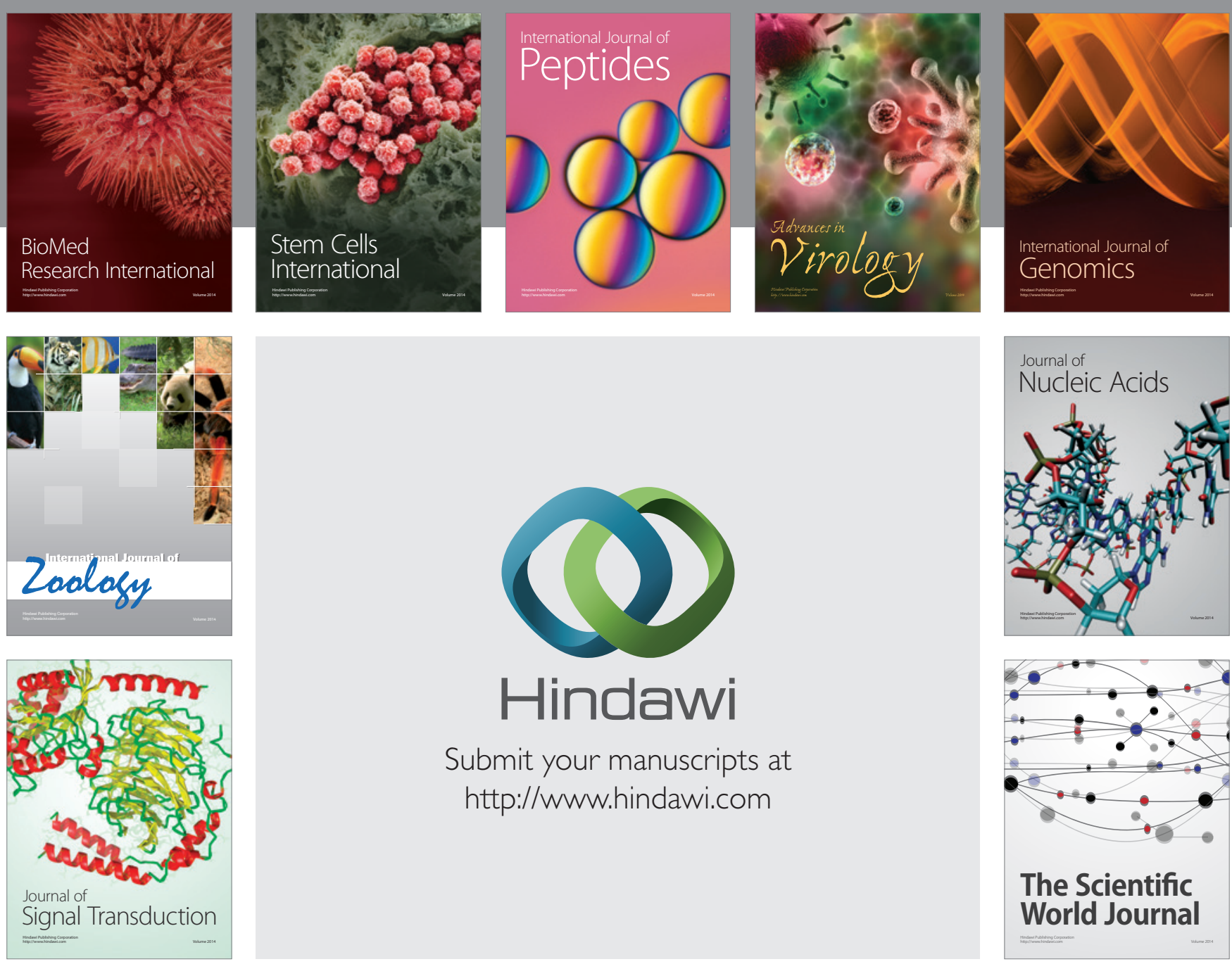

Submit your manuscripts at

http://www.hindawi.com
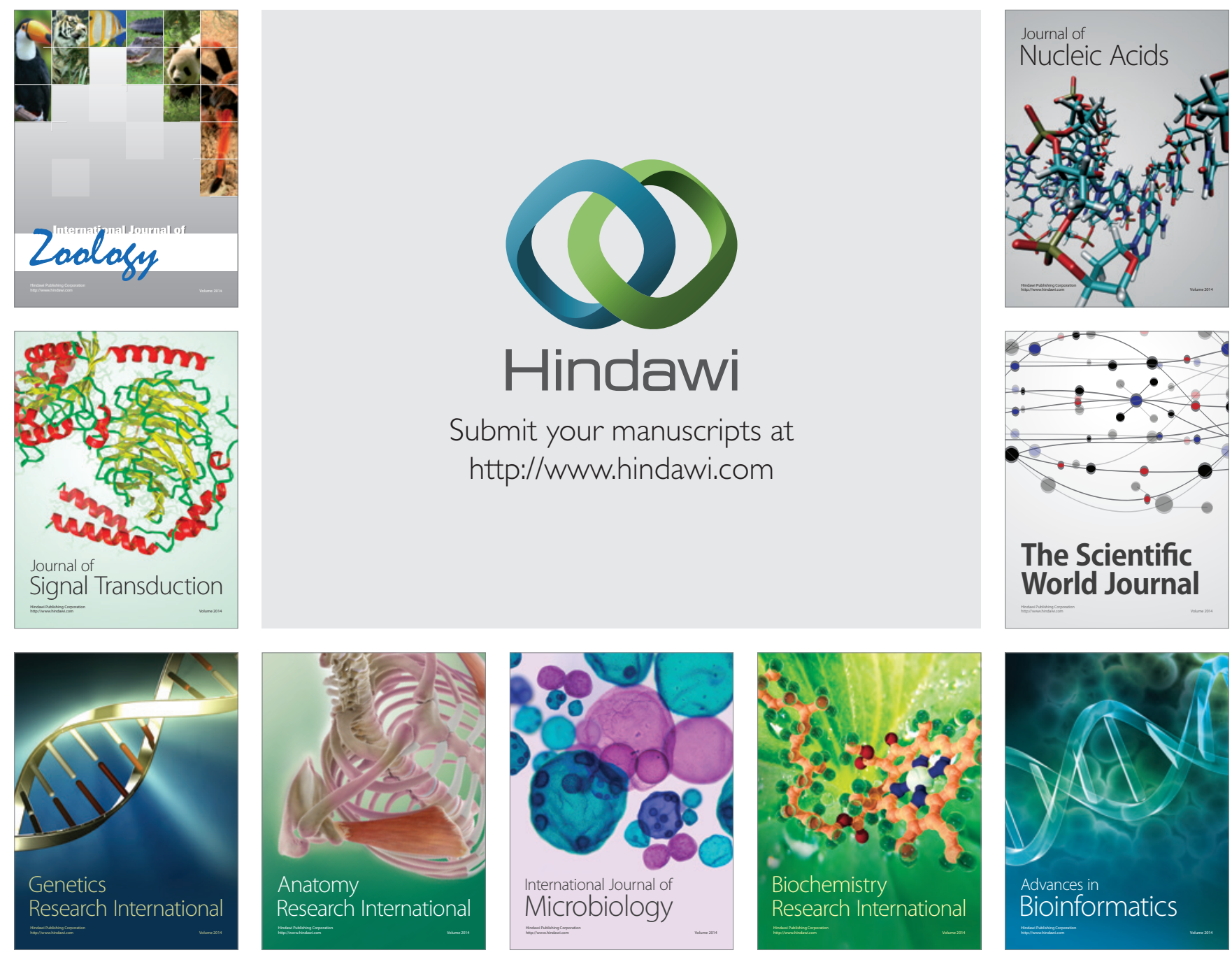

The Scientific World Journal
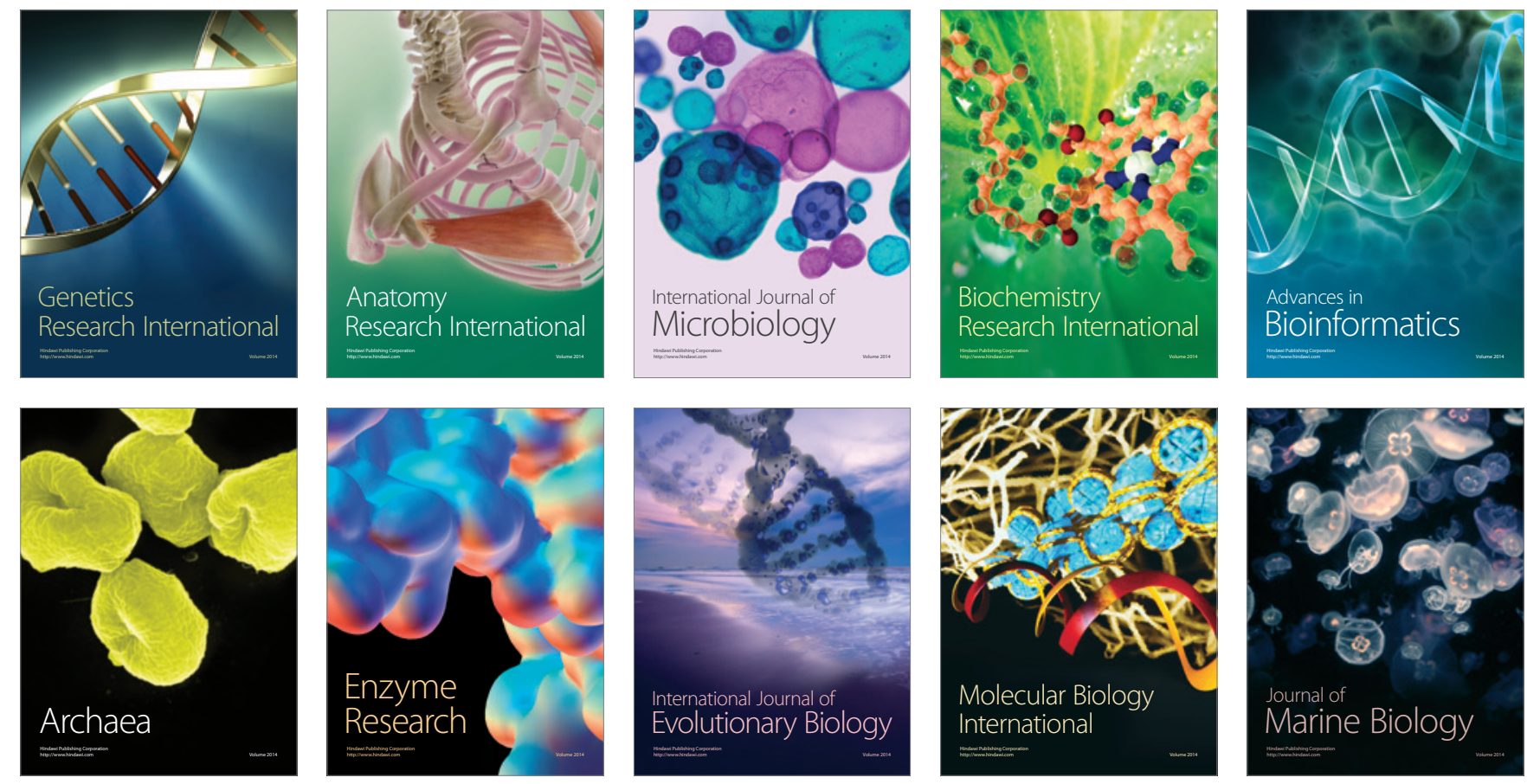